\title{
Relatório de Intercâmbio
}

\section{Universidade Federal do Rio Grande do Sul \\ - University of Texas School of Law}

\author{
Lucas Faria Annes
}

Reproduzo agui alguns trechos da versáo original do relatónio que apresentei à CAPES sobre a minha experiencia como intercambista na University of Texas School of Law. Fui bolsista da FIPSE e da CAPES durante o "spring semester" de 2003. Agradeço gentilmente aos coordenadores do Programa, Prof. Dr. Claudia Lima Marques, Prof. Dr. Cezar Saldarha Souza Junior e Prof. Patricia Isela Hansen pela oportunidade.

Participar de um intercâmbio do Programa de Consórcios em Educaçāo superior BrasilEstados Unidos é uma oportunidade única. Um intercâmbio, em geral, tem a qualidade de fazer com que o intercambista passe a interpretar fenômenos não só com a visão de mundo que adquiriu em seu país de origem, mas também com a visão de mundo do local onde se passa o intercâmbio. Esta capacidade é importantíssima, por exemplo, quando se tomam decisões, pois a correta avaliação das circunstâncias será feita com uma ferramenta a mais, por assim dizer:

Este intercâmbio foi extremamente significativo para mim, visto que atingi meus objetivos após muito trabahlo, e a experiência que adquiri será importantíssima na minha vida profissional. O fato de o intercâmbio ter ocorrido no fim de meus estudos de graduação, mas ainda um ano antes da colação de grau, foi importante, pois viajei com experiência e, além disso, tenho agora a oportunidade de discutir con colegas no Brasil as diferenças entre os sistemas, as vantagens e as desvantagens de cada um, irradiando um sentimento de orgulho pelo que a Universidade Federal do Rio Grande do Sul representa no exterior, betn como apontando características a serem melhoradas.

Ressaltaria a excelência do corpo docente, o acervo impressionante da biblioteca, o ambiente amigável, a importância da University of Texas School of Law em termos nacionais, além da infra-estrutura em geral. O fato de a University of Texas School of Law ser indicada como una das "top 10 law schools" em vários rankings, num país onde existem centenas de escolas de direito, é muito relevante. Além disso, o interesse dos Professores, funcionários e alunos pelo Brasil é muito grande, conforme pode ser atestado pela última edição da revista da UTLaw (http:/wwwtutexas.edu/law/depts/alumni/utlaw/UTLawSummer03.pdh). Pelos contatos que tive com estudantes de diversos outros cursos da University of Texas e pela experiência que tive como aluno desta Universidade, tenho certeza de que as características positivas da School of Law são, em grande parte, qualidades de toda a University of Texas. 
Cursei as cadeiras de Intemational Trade, Corporate Governance, International Petroleum Transactions e International Litigation and Arbitration. Sem qualificar desmedidamente nenhuma das cadeiras, poderia afirmar que os temas mais relevantes e complexos atinentes a cada matéria se faziam presentes nos respectivos conteúdos programáticos. De fato, o conteúdo programático de todas as cadeiras cursadas era realmente atualizado. A conexão da teoria com a prática era muito pertinente, sempre considerando a relevância das informaçôes transferidas para os alunos conforme sua utilidade na vida profissional. O conteúdo foi muito bem desenvolvido pelos Professores. As ementas e demais documentos de apresentação de todas as cadeiras cursadas eram também atuais e refletiam os assuntos que foram estudados e discutidos em aula.

No método socrático, como bem se sabe, os alunos devem estudar previamente o assunto especifico a ser discutido em aula, utilizando como fonte o livro-texto ou livro de casos adotado pelo Professor. Para a cadeira de International Petroleum Transactions foi adotado o livro de mesmo título escrito pelos maiores especialistas da área, incluindo o próprio Professor Enest Smith, que lecionou a cadeira. O livro adotado era bastante atualizado, incluindo casos internacionais novos. Pude verificar a atualidade da obra, por exemplo, quanto aos desenvolvimentos da matéria na América Latina, que foram tratados de maneira muito objetiva. Alén do livro, o Professor distribuía, com freqüência, casos relevantes recentes, de 2003 inclusive, bem como contratos internacionais atuais envolvendo petróleo, normalmente de difícil acesso para alunos. O livro adotado pela Professora Patricia Hansen na cadeira de International Trade havia sido atualizado para o ano de 2003 , sendo que a bibliografia opcional era tanbém atualizada. Em aula, a Professora constantemente se referia a documentos e casos muito recentes, inclusive discutindo com os alunos as conseqüências que poderiam advir destes casos. Na cadeira de International Litigation and Arbitration, o Professor Weintraub adotou seu livro de casos, atualizado com suplemento para o ano de 2003. Além disso, indicou seu livro "Commentary on the Conflict of Laws" como leitura opcional. Como os demais Professores, o Professor Weintraub referiu-se diversas vezes a novos casos, indicando referência para busca pelos alunos. Finalmente, a aula de Corporate Governance foi basicamente calcada na "reforma" da governança corporativa (decorrente dos escândalos corporativos, como o caso Enron e o caso Tyco) e, por isso mesmo, as referências bibliográficas eram muito atuais. Foi adotado o livro de casos da Harvard Business School.

O método de ensino utilizado foi o socrático, como já zeferido. Os alunos devem estudar uma matéria especifica do livro adotado pelo Ptofessor (geralmente é indicada no syllabus a leitura de páginas X $\mathrm{X}$ para cada dia de aula). Assim, o Professor parte do pressuposto de que todos os alunos chegam à sala de aula conhecendo a fundo a matéria que será tratada, podendo concentrar-se em ressaltar os pontos mais importantes e discutir com os alunos as questōes mais controversas. Uma das características do ensino que mais me chamou a atenção foi o foco dos Professores na matéria específica em discussão. En três cadeiras, com exceção de Corporate Governance, tínhamos três encontros semanais de 50 minutos cada. Assim, as aulas eram muito densas do início ao fim dos 50 minutos, pois o Professor deveria finalizar a matéria prevista para aquele dia e deixar os alunos em condições para estudar o assunto da aula 
seguinte. Este sistema de aulas "pulverizadas" durante a semana, combinado com una rígida e transparente programação de conteúdos permitiu-me acompanhar muito bem as aulas, ocupando-me quase que diariamente com cada uma das cadeiras. Todas as cadeiras que cursei baseavam-se no método socrático, com pequenas variantes: na cadeira de International Trade Law, os alunos poderiam escolher a data em que seriam chamados pelo Professor para discutir a matéria - obviamente isto năo impedia os alunos de fazerem perguntas e participar em dias para os quais não estivessem inscritos. Nas cadeiras de International Litigation and Arbitration, Corporate Governance e International Petroleum Transactions os Ptofessores chamavam os alunos aleatoriamente.

Creio que os objetivos dos Professores em cada cadeira foram alcançados. Um dos indicativos é o fato de os syllabus terem sido seguidos conforme o programado. Da mesma forma, posso afirmar também que meus objetivos de aprendizado em cada cadeira foram alcançados. Estudei muito bem toda a materia prevista, adaptei-me rapidamente ao ambiente de estudo e ao método de ensino diferentes.

Gostaria de ressaltar algumas particularidades do sistema de avaliação encontrado na University of Texas School of Law. A verificação por provas é muito organizada. A data das provas, por exemplo, já é definida bem antes do início do semestre, o que possibilita aos alunos um planejamento de escolha de cadeiras, também considerando a proximidade temporal das provas finais. Os colegas ameticanos da University of Texas School of Law estäo habituados a escolher cadeiras de maneira que possam realizar provas com um intervalo mínimo de quatro dias, conforme pude constatar. É interessante notar que, antes de minha saída do Brasil, já sabia a data de minhas provas. O local onde a prova deve ser aplicada somente é divulgado por email, na noite anterior à realização da mesma. Os alunos têm a opção de realizar a prova num laptop. Existe um programa que bloqueia o acesso a qualquer outra função do computador que não estritamente voltada para a realização da prova. A única vantagem que os alunos intercambistas têm em relação aos colegas americanos é a possibilidade de realizar a prova em $50 \%$ a mais de tempo. Assim, se ela está programada para durar 4 horas, o aluno intercambista terá direito a realizá-la por 6 horas.

As provas não são identificadas com nomes para que o Professor não seja influenciado ao realizar a correção, en virtude de conhecer ou desconhecer determinado aluno. Nem mesmo as notas funais são de conhecimento do Professor, já que a contabilização final é feita pela Secretaria, onde as notas das provas entregues pelo Professor são atribuídas aos alunos conforme suas numerações e somadas às notas relativas à participaçăo em aula ou a outros trabalhos. As notas finais somente são conhecidas pelos alunos. Assim, foi necessária uma autorização expressa por escrito dos alunos intercambistas para que a secretária do LL.M., que era responsável por alguns assuntos práticos do intercâmbio, pudesse encaminhar os nossos boletins de desempenho após o nosso retomo ao Brasil É importante ressaltar que as notas finais na University of Texas School of Law obedecem ao sistema de "curva", pelo qual o número de conceitos $\mathrm{A}$, por exemplo, corresponderá a um percentual pré-determinado de alunos de determinada cadeira. 
Nas cadeiras de Intemational Litigation and Arbitration e International Trade, a nota final é basicamente a nota da prova. Na cadeira de Intemational Petroleum Transactions, a nota final é composta das notas de dois memorandos de cinco páginas cada, entregues durante o decorrer do semestre, e uma monografia de 25 páginas ou uma prova final. Optei pela monografia. Analisei casos envolvendo o sistema de solução de controvérsias do Gasoduto Bolívia-Brasil. A avaliação de Corporate Governance foi feita conforme um sistema de participaçáo dos alunos em uma de duas monografias, cada uma com 150 páginas aproximadamente. O aluno tinha três opçóes, que dependiam da concordância dos demais: ser líder geral de uma das monografias, ser líder responsável por um dos capítulos da monografia ou exercer função de auxilio aos líderes. Os auxiliares, a grande maioria da turma, deveriam fazer prova. Como fui responsável por um dos capítulos de uma monografia, fui avaliado pela participação em aula, realização das tarefas extra classe, pela nota confidencialmente atribuída a mim por colegas da classe e, finalmente, pela qualidade do capítulo que coordenei.

Gostaria de salientar que, se porventura um Professor não pudesse lecionar em determinado dia, os alunos recebiam aviso, com a devida antecedência, e sempre tinham a opção de assistir a uma aula de recuperação em dia e horários alternativos. Caso o aluno não pudesse comparecer no dia e horário marcados, poderia assistir individualmente ao vídeo da aula. Devo frisar também que a biblioteca jurídica, com mais de um milhão de volumes, é extremamente organizada. Outra ferramenta que me auxiliou muito na realização de tarefas e no acompanhamento da matéria foi o chamado "Blackbord". Este serviço permite que os alunos consultem pela Internet todas as infomações pertinentes à cadeira que estão cursendo. Assim, os alunos têm acesso a documentos, casos, publicaçôes especializadas, notícias de jornal envolvendo a materia, avisos do Professor, calendário, programação de cada dia de aula com a matéria a ser discutida, endereço eletrônico de todos os colegas, horários e sala de aula, informações para contato com o Professor. Como depende da participação do Professor para funcionar e ainda não é obrigatória, esta ferramenta somente foi utilizada pelos Professores Patricia Hansen e Whilliam Cunningham.

Destaco igualmente a organização dos diversos outros corpos que compõem a faculdade, como as várias revistas jurídicas, de que os alunos podem participar, organizando conferências e outras atividades, o "centro acadêmico" (Student Bar Association), as organizaçōes de alunos, como a de alunos "chicanos", a de alunos negros e a de mestrandos, etc.

Poderia citar como facilidades os horários flexiveis da biblioteca, que ficava aberta até as 2 da manhãe abria aos domingos, a rede wireless de acesso à Internet, os meios de integração com alunos e o grande número de funcionários, altamente qualificados e sempre simpáticos e dispostos a ajudar. Citaria, ainda, a constante disponibilidade dos Professores para resolver dúvidas, além do procedimento, que me pareceu padrão, já que vi oconter várias vezes, de que quando o Próessor não soubesse responder a indagação no mesmo momento ou a explicação por algum motivo não pudesse ter sido a mais completa, o Professor entregavá pesquisa parao aluno, sobre o ponto perguntado, no dia seguinte.

A adaptação ao sistema de ensino e ao local, bem como a convivência com os colegas americanos ocorreram de maneira muito natural. Obviamente, deparei-me com muitas 
diferenças em relação ao Brasil, porém considero que minha adaptação tenha sido rápida. Minha experiência como bolsista do AFS na Alemanha durante um ano foi muito importante.

No caso da University of Texas School of Law o número de intercambistas de 1 semestre é muito mais baixo durante o "spring semester". Isto se reflete, por exemplo, na maior disponibilidade de tempo para cada intercambista por parte dos funcionários encarregados de tratar das questôes envolvendo o intercâmbio. Creio que, no geral, o "spring semester" propicia aos alunos brasileiros uma maior proximidade com alunos, Professores e funcionários.

Gostaria de agradecer à CAPES pela oportunidade, ressaltando a importância dos laços institucionais entre CAPES, FIPSE, University of Texas e Universidade Federal do Rio Grande do Sul. Fico muito lisonjeado em saber que meu esforço durante o intercâmbio nos Estados Unidos tenha contribuído para a união e a cooperação entre estas instituiçōes. 